\title{
Impact of HHP processing on volatile profile and sensory acceptance of Pêra-Rio orange juice
}

\author{
Raíssa Bittar Mastello ${ }^{\mathrm{a}}$, Natália Soares Janzantti ${ }^{\mathrm{b}}$, Antônio Bisconsin-Júnior ${ }^{\mathrm{a}}$, Magali Monteiro ${ }^{\mathrm{a}, *}$ \\ a São Paulo State University (UNESP), School of Pharmaceutical Sciences, Department of Food and Nutrition, 14801-902 Araraquara, SP, Brazil \\ b São Paulo State University (UNESP), Institute of Biosciences, Humanities and Exact Sciences, Department of Food Engineering and Technology, 15054-000 São José do \\ Rio Preto, SP, Brazil
}

\section{A R T I C L E I N F O}

Chemical compounds studied in this article: Hexanal (PubChem CID: 6184)

Ethyl butanoate (PubChem CID: 7762)

Heptanal (PubChem CID: 8130)

$\alpha$-Pinene (PubChem CID: 6654)

$\beta$-Pinene (PubChem CID: 14896)

$\beta$-Myrcene (PubChem CID: 31253)

Octanal (PubChem CID: 454)

Cymene (PubChem CID: 7463)

D-Limonene (PubChem CID: 440917)

Trans- $\beta$-ocimene (PubChem CID: 5281553)

Cis-ß-ocimene (PubChem CID: 5320250)

$\gamma$-Terpinene (PubChem CID: 7461)

1-Octanol (PubChem CID: 957)

Terpinolene (mixture) (PubChem CID: 11463)

Linalool (PubChem CID: 6549)

Nonanal (PubChem CID: 31289)

p-Mentha-1,3,8-triene (PubChem CID: 176983)

Ethyl 3-hydroxyhexanoate (PubChem CID:

61293)

Alloocimene (PubChem CID: 5368821)

Terpinen-4-ol (PubChem CID: 11230)

$\alpha$-Terpineol (PubChem CID: 17100)

Ethyl octanoate (PubChem CID: 7799)

Decanal (PubChem CID: 8175)

Octyl acetate (PubChem CID: 8164)

Carveol (PubChem CID: 7438)

Nerol (PubChem CID: 643820)

$\beta$-Citronellol (PubChem CID: 8842)

Carvone (mixture) (PubChem CID: 7439)

Geraniol (PubChem CID: 637566)

Linalyl acetate (PubChem CID: 8294)

Perillaldehyde (PubChem CID: 16441)

Undecanal (PubChem CID: 8186)

Citronellyl acetate (PubChem CID: 9017)

Neryl acetate (PubChem CID: 1549025)

$\alpha$-Copaene (PubChem CID: 19725)

$\delta$-Elemene (PubChem CID: 12309449)

Geranyl acetate (PubChem CID: 1549026)

$\gamma$-Elemene (PubChem CID: 6432312)

Longifolene (PubChem CID: 289151)

Dodecanal (PubChem CID: 8194)

Caryophyllene (PubChem CID: 5354499)

\begin{abstract}
A B S T R A C T
The purpose of this study was to evaluate volatile compounds and sensory acceptance of HHP processed orange juice compared with non-processed and pasteurized orange juices. RSM and sniffing were successfully applied for optimization of HS-SPME conditions. The chosen HS-SPME conditions $37{ }^{\circ} \mathrm{C}$ during 25 min of exposure properly characterized the volatile profile of HHP processed, pasteurized and non-processed orange juices. HHP processing conditions had an impact on the volatile profile of the juice. Sensory acceptance was higher for nonprocessed and similar for HHP and pasteurized orange juice. PCA discriminated processed from non-processed orange juice, and HHP from pasteurized orange juice. HHP processed orange juice was characterized by ethyl butanoate, octanal, 1-octanol, linalool, ethyl 3-hydroxyhexanoate, nootkatone and ethyl octanoate. Pasteurized orange juice was characterized by the same compounds as HHP, plus geranyl acetate and apart from ethyl octanoate. Terpinolene, octyl acetate, carveol, carvone, linalyl acetate and $\delta$-elemene characterized non-processed orange juice.

Industrial relevance: HHP processing has been used as an efficient food preservation process in order to meet consumers growing demand for juices with natural-like attributes. Orange juice HHP processing is claimed to inactivate PME and eliminate microorganisms by pressurizing the juice, maintaining freshness, sensorial and nutritive value. This technology is still not being used by the Brazilian juice industry, which presents itself as a whole range of opportunities. Therefore the focus on volatile compounds from Pêra-Rio orange juice is due to its importance for Brazilian citrus industry. In this study orange juice pressurized in a pilot plant was compared to the non-processed and pasteurized orange juice, presenting a new approach for the analysis of volatile compounds, using RSM HS-SPME optimization combined with sniffing, and most importantly, considering the aroma representativeness, in order to properly evaluate the impact of HHP processing on the volatile compounds, responsible for the flavor of the juice and discriminate the volatile profile of the HHP orange juice compared with non-processed and pasteurized orange juice. Sensory acceptance of HHP processed orange juice was also performed to verify if changes in volatile profile were perceived by consumers.
\end{abstract}

\footnotetext{
* Corresponding author at: Rodovia Araraquara-Jaú, Km 01 s/n, Campos Ville, Araraquara, SP 14800-903, Brazil.

E-mail address: monteiro@fcfar.unesp.br (M. Monteiro).
} 
$\beta$-Copaene (PubChem CID: 57339298)

Humulene (PubChem CID: 5281520)

Valencene (PubChem CID: 9855795)

Eremophilene (PubChem CID: 12309744)

$\delta$-Cadinene (PubChem CID: 12306054)

Caryophilene oxide (PubChem CID: 14350)

Selina-3,7(11)-diene (PubChem CID: 522296)

Nootkatone (PubChem CID: 1268142)

Keywords:

HS-SPME

Orange juice

HHP processing

Volatile compounds

Sensory acceptance

PCA

\section{Introduction}

Orange juice is the world's most consumed fruit juice, with an estimated consumption of 1.8 billion liters a year globally (United States Department of Agriculture, 2016). Brazil is the leader in production and exportation of orange juice worldwide. Brazil exports $>$ $90 \%$ of its orange juice production and is responsible for $>50 \%$ of orange juice globally consumed. Of five orange juice glasses consumed in the world three are from Brazil. Pêra-Rio is the most important variety cultivated in Brazil, accounting for the singleness and the characteristics of the Brazilian orange juice (CitrusBR, 2017; Neves et al., 2009).

Orange juice properties can be changed by microorganisms and enzymes, and to prolong the shelf life, thermal processing is the most widely used processing technique, successfully inactivating them. Thermal processing may have a negative impact on orange juice quality, such as loss of flavor and aroma compounds (Janzantti, Machado, \& Monteiro, 2011; Mastello, Janzantti, \& Monteiro, 2015), degradation of ascorbic acid and color changes. Some studies have identified and quantified the volatile compounds of orange juice, comparing different processing techniques and their effects on volatile compounds composition, sensory profile and physicochemical characteristics (Baxter, Easton, Schneebeli, \& Whitfield, 2005; Bull et al., 2004; Mastello, Janzantti, et al., 2015; Vervoort et al., 2012).

Following the growing demand of juices with natural-like attributes, non-thermal processing techniques such as high hydrostatic pressure processing (HHP) and ultra high pressure homogenization processing (UHPH), pulsed electric fields (PEF), ultrasound and ohmic heating treatment have been investigated (Achir et al., 2016; Bisconsin-Junior, Rosenthal, \& Monteiro, 2014; Samani, Khoshtaghaza, Lorigooini, Minaei, \& Zareiforoush, 2015; Timmermans et al., 2011; VelázquezEstrada, Hernández-Herrero, Guamis-López, \& Roig-Sagués, 2012; Vervoort et al., 2011). In fact HHP has currently been used in several raw and processed food categories (Rendueles et al., 2011; Sampedro, Geveke, Fan, \& Zhang, 2009), and depending on the processing conditions, effects on color, flavor and texture affecting quality have been reported (Bajovic, Bolumar, \& Heinz, 2012; El Hadi, Zhang, Wu, Zhou, \& Tao, 2013; Oey, Lille, Loey, \& Hendrickx, 2008; Wang et al., 2013). HHP processing is still not being used in Brazil and this study represents a starting point for the Brazilian citrus industry, providing information over flavor changes and sensorial losses of orange juice HHP processed.

HHP processing inactivates the heat-stable pectin methylestearase (PME) and eliminates microorganisms by pressurizing the juice instead of heating, and if appropriately applied, this processing is claimed to maintain freshness, sensorial and nutritive value of orange juice (Baxter et al., 2005; Bisconsin-Junior et al., 2014; Bull et al., 2004; Parish, 1998; Vervoort et al., 2012). Orange juice aroma can be influenced by different varieties, maturity, storage and processing conditions. There are few studies in the literature evaluating the effects of HHP in orange juice aroma. The HHP conditions applied in this work were chosen through the results of the study of BisconsinJunior et al. (2014). Different pressure, temperature and time combinations were evaluated on Pêra-Rio orange juice using an experimental design and the optimal condition was defined based on its capacity to reduce PME residual activity below $20 \%$ and microbial count lower than $2 \log \mathrm{UFC} / \mathrm{mL}$.

Headspace Solid Phase Microextraction (HS-SPME) technique has been largely applied to volatile compounds analysis combined with gas chromatography-mass spectrometry (GC-MS) (Mastello, Capobiango, Chin, Monteiro, \& Marriott, 2015; Murat, Gourrat, Jerosch, \& Cayot, 2012; Rega, Fournier, \& Guichard, 2003). A careful optimization of the SPME conditions is necessary to determine the best conditions to analyze volatile compounds of orange juice. Factorial design enables the evaluation of many variables and their interaction with the response variables. Response Surface Methodology (RSM) explores the relationship between independent variables and one or more response variables (Montgomery \& Wiley, 2001; Myers, Montgomery, \& Anderson-Cook, 2009). In this study the aroma representativeness was combined with HS-SPME optimization considering the volatile profile of the juice to minimize the effect of different processing on the juice, in order to make a fair comparison among them. Moreover, sensory acceptance of HHP processed orange juice was also performed to verify if changes in volatile profile were observed by the consumers.

The aim of this work was to evaluate the volatile compounds and sensory acceptance of the HHP processed orange juice. The influence of exposure time and temperature on the volatile compounds profile and area was assessed using RSM, also considering the aroma representativeness, to choose the HS-SPME conditions for the analysis of different orange juices.

\section{Material and methods}

\subsection{Orange juice for HS-SPME optimization and analysis}

The orange juice of Pêra-Rio variety from the frozen concentrated orange juice (FCOJ) processing was supplied by a company from Araraquara, SP, Brazil. The FCOJ processing consists of a series of operations. Fruits are selected, washed and directed to the extraction in a FMC Citrus Juice Extractor, the most used in the Brazilian citrus plants. The juice follows to the finisher to remove pulp and vesicles (finishing step) and then to a multiple-effect evaporator TASTE (Thermally Accelerated Short Time Evaporator) for concentration, in order to evaporate water up to $66^{\circ} \mathrm{Brix}$ (Nagy \& Chen, 1993). Orange juice from the finishing step $\left(11.8{ }^{\circ} \mathrm{Brix}\right)$ of the FCOJ processing was used in the experimental design.

Orange of the Pêra-Rio variety cultivated in Bauru, SP, Brazil $\left(22^{\circ} 25^{\prime} 59^{\prime \prime} \mathrm{S}, 49^{\circ} 10^{\prime} 31^{\prime \prime} \mathrm{W}\right)$, during the $2012 / 2013$ harvest was submitted to extraction in a FMC Citrus Juice Extractor and finishing at the JBT Food Tech Citrus System, Araraquara, SP, Brazil, called non- 
processed $\left(9.5^{\circ} \mathrm{Brix}\right)$. For the HHP treatment, non-processed orange juice was pressurized at $520 \mathrm{MPa}, 60^{\circ} \mathrm{C}$, for $360 \mathrm{~s}\left(9.5^{\circ} \mathrm{Brix}\right)$ in a Stansted Food Lab 9000 (Stansted Fluid Power, Stansted, UK) pilot equipment, which conditions were described by Bisconsin-Junior et al. (2014). For pasteurization non-processed orange juice was put in a Armfield FTD25D SSHE (Armfield, UK) tubular heat exchanger at $95{ }^{\circ} \mathrm{C}$ for $30 \mathrm{~s}$ (Braddock, 1999), and later cooled to $20^{\circ} \mathrm{C}$ (9.7 $\left.{ }^{\circ} \mathrm{Brix}\right)$. The volatile compounds of the non-processed, pasteurized and HHP processed orange juices were evaluated.

\subsection{HS-SPME sampling}

Firstly, the headspace solid phase microextraction (HS-SPME) fibers PDMS, PDMS/DVB and PDMS/DVB/CAR were tested in order to choose which one adsorbed the higher amount of volatile compounds and showed the highest total area in the chromatogram. The PDMS/DVB/ CAR fiber, with large polarity range was chosen.

The HS-SPME extraction was performed using a $10 \mathrm{~mm}$ length 50/ $30 \mu \mathrm{m}$ PDMS/DVB/CAR fiber (Supelco, Bellefonte, PA, USA). $10 \mathrm{~mL}$ of orange juice was transferred to a $20 \mathrm{~mL}$ vial sealed with PTFE silicone septa (Supelco, Bellefonte, PA, USA), containing a magnetic stirring bar (31.42 $\left.\mathrm{rad} \mathrm{s}^{-1}\right)$. After a $17 \mathrm{~min}$ equilibration time, the fiber was exposed to the sample headspace according to the conditions established on the experimental design. The fiber was previously conditioned following the manufacturer's instructions.

\subsection{Experimental design}

A central composite design (CCD) of two independent variables containing a $2^{2}$ factorial design, 4 axial points and 3 repetitions of the central point, totalizing 11 essays was used (Myers et al., 2009) to optimize the HS-SPME extraction parameters (extraction time and temperature). The levels of the independent variables were coded as -1 and +1 , representing the levels of $2^{2}$ factorial design; 0 (zero), representing the central point of the design, which made it possible to estimate the lack of fit of the statistical model and the pure error; and -1.41 and +1.41 , representing the axial points, allowing a quadratic statistical model (Table 1 ).

RSM was used to evaluate the effect of the independent variables (exposure time and temperature) on the total area of peaks on the chromatograms (response variable) of orange juice from the finishing step of FCOJ processing.

\subsection{GC-FID analysis}

A Shimadzu 17-A was used to the GC-FID analysis. The capillary column was DB-5 $(30 \mathrm{~m} \times 0.25 \mathrm{~mm} \times 0.25 \mu \mathrm{m})$. The GC inlet was set at $250{ }^{\circ} \mathrm{C}$ and the fiber was exposed in the inlet for $2 \mathrm{~min}$ in splitless mode. The hydrogen carrier flow rate was $1.70 \mathrm{~mL} \mathrm{~min}^{-1}$. The oven was programmed at $40{ }^{\circ} \mathrm{C}$ hold for $3 \mathrm{~min}$, ramp of $3{ }^{\circ} \mathrm{C} \mathrm{min}{ }^{-1}$ up to $160{ }^{\circ} \mathrm{C}$; and then $10^{\circ} \mathrm{C} \mathrm{min}^{-1}$ up to $230{ }^{\circ} \mathrm{C}$ and hold for $2 \mathrm{~min}$. The FID temperature was $250{ }^{\circ} \mathrm{C}$. A series of alkanes $\left(\mathrm{C}_{8}-\mathrm{C}_{20}\right)$ was employed to establish the retention indices in the HP-5MS column (van Den Dool \& Kratz, 1963), that was also compared with those from the GC-MS.

Peak area of orange juice volatile compounds from HHP processed, non-processed, pasteurized and from the finishing step of FCOJ processing were analyzed by GC-FID.

\subsection{GC-MS analysis}

GC-MS analysis was performed using an Agilent 7890A gas chromatograph coupled with a 5975C mass spectrometer. A HP-5MS column $(30 \mathrm{~m} \times 0.25 \mathrm{~mm} \times 0.25 \mu \mathrm{m})$ (Agilent, Santa Clara, CA, USA), maintained at $40{ }^{\circ} \mathrm{C}$ for $3 \mathrm{~min}$, then set to $160^{\circ} \mathrm{C}$ at $3{ }^{\circ} \mathrm{C} \mathrm{min}{ }^{-1}$, and set to $230{ }^{\circ} \mathrm{C}$ at $10^{\circ} \mathrm{C} \mathrm{min}^{-1}$ and held for $10 \mathrm{~min}$. The GC inlet was set at $250{ }^{\circ} \mathrm{C}$ and the fiber was exposed in the inlet for $2 \mathrm{~min}$ in splitless mode. The helium carrier flow rate was $1.7 \mathrm{~mL} \mathrm{~min}^{-1}$. The DB-Wax column $(30 \mathrm{~m} \times 0.25 \mathrm{~mm} \times 0.25 \mu \mathrm{m})(\mathrm{J} \& \mathrm{~W}$, Folsom, CA, USA) was programmed at $40{ }^{\circ} \mathrm{C}$ for $5 \mathrm{~min}$, with ramp of $3{ }^{\circ} \mathrm{C} \mathrm{min}{ }^{-1}$ up to $200{ }^{\circ} \mathrm{C}$ for $10 \mathrm{~min}$, with a helium carrier flow rate of $1.0 \mathrm{~mL} \mathrm{~min}^{-1}$. Transfer line temperature was maintained at $280^{\circ} \mathrm{C}$. The quadrupole mass spectrometer was operated in the electron impact mode $(70 \mathrm{eV})$ and the source temperature was $230^{\circ} \mathrm{C}$, with a mass/charge range of 35-350 amu.

Volatile compounds from HHP processed, non-processed and pasteurized orange juice were identified by GC-MS. The identification of the compounds was based on their mass spectra compared to the NIST library (v. 2.0) and pure standards in the HP-5MS and DB-Wax columns. An alkane solution $\left(\mathrm{C}_{8}-\mathrm{C}_{20}\right)$ was employed to obtain the retention indices in the two columns (van Den Dool \& Kratz, 1963), that were also compared with those of the literature (Acree \& Arn, 2016; Mastello, Capobiango, et al., 2015) and of pure standards.

\subsection{Sniffing}

The sniffing tests were carried out on a Shimadzu GC-2010 (Kyoto, Japan) equipped with a SGE olfactory port (ODO II model, Texas, USA). The conditions of HS-SPME exposure time and temperature of the juice were at $27^{\circ} \mathrm{C}, 22 \mathrm{~min}$ in the essay $2 ; 37^{\circ} \mathrm{C}, 25 \mathrm{~min}$ in the essay 6 and $47^{\circ} \mathrm{C}, 22 \mathrm{~min}$ in the essay 4 . Each condition was evaluated by a panel of four previously selected and trained panelists. The panel described how characteristic of orange juice was the odour perceived. The volatile compounds were directly desorbed into the injection port of the GC and were immediately conducted to the sniffing port throughout an inactivated column of $1 \mathrm{~m}$ (length) $\times 0.25 \mathrm{~mm}$ (i.d.). Hydrogen was used as the carrier gas, with a flow rate of $10 \mathrm{~mL} \mathrm{~min}^{-1}$. The volatile compounds were instantaneously transferred from the injection port to the olfactory port at the same temperature to avoid separation. Therefore the injection port, inactivated column and sniffing port were maintained at a temperature of $250{ }^{\circ} \mathrm{C}$.

\subsection{Sensory evaluation}

The acceptance test was carried out by 49 consumers (undergraduate students, college staff and servers) from both genders, from 18 to 50 years old, that liked at least moderately and consumed at least once a month in natura and pasteurized orange juice. Color, overall impression, aroma, flavor and texture of orange juice were evaluated using a 9-point hedonic scale $(9=$ like extremely, $5=$ neither like nor dislike, $1=$ dislike extremely). Besides, consumers were asked to describe what they appreciate most and least in the juice.

Table 1

The central composite design (CCD) and experimental response values for orange juice.

\begin{tabular}{|c|c|c|c|c|c|c|}
\hline \multirow[t]{2}{*}{ Essay } & \multicolumn{4}{|c|}{ Independent variable } & \multicolumn{2}{|l|}{ Response variable } \\
\hline & $\mathrm{t}(\mathrm{min})$ & $\mathrm{T}\left({ }^{\circ} \mathrm{C}\right)$ & \multicolumn{2}{|c|}{ Values of levels } & Total area $(\mu \mathrm{V})$ & Total area \\
\hline 1 & 8 & 27 & -1 & -1 & $19,824,706$ & $1,574,464$ \\
\hline 2 & 22 & 27 & +1 & -1 & $17,358,995$ & $1,924,398$ \\
\hline 3 & 8 & 47 & -1 & +1 & $15,019,967$ & $2,207,612$ \\
\hline 4 & 22 & 47 & +1 & +1 & $15,400,700$ & $2,626,209$ \\
\hline 5 & 5 & 37 & -1.41 & 0 & $21,537,482$ & $1,811,641$ \\
\hline 6 & 25 & 37 & +1.41 & 0 & $21,298,419$ & $2,290,790$ \\
\hline 7 & 15 & 23 & 0 & -1.41 & $22,722,280$ & $1,723,221$ \\
\hline 8 & 15 & 51 & 0 & +1.41 & $16,972,519$ & $2,897,193$ \\
\hline 9 & 15 & 37 & 0 & 0 & $14,068,104$ & $2,081,370$ \\
\hline 10 & 15 & 37 & 0 & 0 & $12,841,447$ & $1,927,941$ \\
\hline 11 & 15 & 37 & 0 & 0 & $12,841,447$ & $2,015,300$ \\
\hline
\end{tabular}




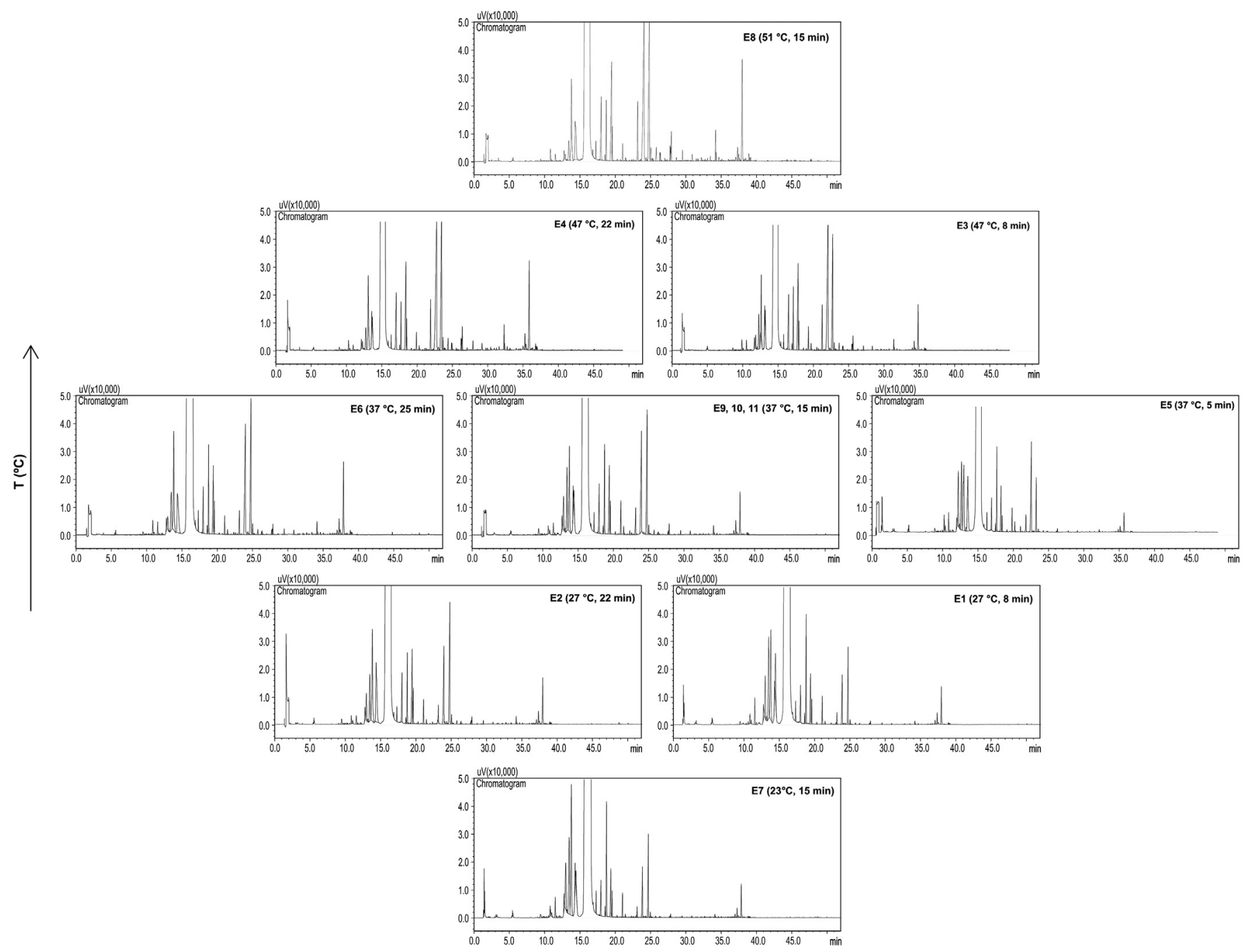

Fig. 1. GC-FID chromatograms of the 11 essays.

Thirty milliliters of HHP processed, non-processed and pasteurized orange juice sat $12{ }^{\circ} \mathrm{C}$ were offered in $50 \mathrm{~mL}$ disposable plastic glasses, coded with random three-digit numbers. The samples were presented in a monadic and randomized order to avoid the first-order and carry-over effects (Macfie, Bratchell, Greenhoff, \& Vallis, 1989). The test was carried out in standardized sensory booths. Spring water and unsalted cracker were provided for mouth rinsing among samples.

\subsection{Data analysis}

Analysis of variance of the regression equations allowed the adequacy of the model to be determined by evaluating the lack of fit, coefficient of determination $\left(\mathrm{R}^{2}\right), \mathrm{F}$ test value and significance of the effects. A significance level of $5 \%(\mathrm{p} \leq 0.05)$ was used for the central composite design. Student $t$-test $(\mathrm{p} \leq 0.05)$ was used to compare means of the quantified volatile compounds for HHP and non-processed orange juices.

One-way analysis of variance (ANOVA) and means Tukey test were applied in the sensory results. The principal component analysis (PCA) was carried out using the volatile compounds areas and sensory acceptance means for the HHP processed, non-processed and pasteurized orange juices, in order to discriminate the juices. Variables highly correlated (rotate component matrix $\geq 0.95$ ) with each principal component were considered.
All the statistical analysis were performed using STATISTICA ${ }^{\circledR} 8.0$ Software (Stat Soft, Tulsa, USA).

\section{Results and discussion}

RSM was used to optimize the HS-SPME conditions for the analysis of orange juice volatile compounds. At first, the effect of exposure time and temperature on the total area of the chromatograms from each essay of the CCD was evaluated (Table 1, Fig. 1). The analysis of variance indicated that both exposure time and temperature (linear and quadratic) were significant $(\mathrm{p} \leq 0.05)$ for the model in the experimental design, with a regression model $\mathrm{F}$ value of 4.66 ( $\mathrm{p} \leq 0.05)$. The coefficient of variation was $5.34 \%$ and $\mathrm{R}^{2}$ was 0.68 (Table 2). Using the regression coefficients from the adjusted model the following equation was generated: $\mathrm{y}=6,2063,306-1,486,476 . \mathrm{t}+53591 . \mathrm{t}^{2}-1,875,504 . \mathrm{T}+22,817 . \mathrm{T}^{2}$, where $\mathrm{t}=$ time and $\mathrm{T}=$ temperature. The model showed inconsistency and lack of adjustment. The response surface showed that higher areas were obtained with lower temperature and lower exposure time; lower temperature and higher exposure time; and higher temperature and higher exposure time (Fig. 2a). The inclusion of other criteria was then necessary. As the volatile compound D-limonene represents about $85 \%$ of the total peak area (Bylaite \& Meyer, 2006), it may be affecting the total area and possibly masking the response of the other compounds in the chromatogram. Thus the response variable chosen was the total area discounting D- 
Table 2

Analysis of variance (F value) and coefficient of variation (CV) for total area and total area without limonene.

\begin{tabular}{lll}
\hline \multirow{2}{*}{ Source of variation } & Total area & Total area without limonene \\
\cline { 2 - 3 } & F value & \\
\hline Regression model & $4.66^{*}$ & $5.29^{*}$ \\
$t$ & $93.14^{* *}$ & $44,11^{* *}$ \\
$t^{2}$ & $52.73^{* *}$ & $n s$ \\
$T$ & $55.24^{* *}$ & $189,12^{* *}$ \\
$T^{2}$ & $56.00^{* *}$ & $n s$ \\
Lack of fit & $20.20^{*}$ & $3.84, n s$ \\
CV (\%) & 5.34 & 3.83 \\
$\mathrm{R}^{2}$ & 0.68 & 0.90 \\
\hline
\end{tabular}

$T=$ temperature, $t=$ time, $n s=$ not significant

${ }^{*} \mathrm{p} \leq 0.05$

*** $\mathrm{p} \leq 0.01$.

limonene area (Table 1). The analysis of variance showed that both linear exposure time and temperature were significant $(\mathrm{p} \leq 0.05)$ for the model in the experimental design, with a regression model $\mathrm{F}$ value of 5.29 ( $p \leq 0.05$ ). The coefficient of variation was $3.83 \%$ and $R^{2}$ was 0.90 (Table 2). Using the regression coefficients from the adjusted model the following equation was generated: $y=321,441+25,684 . t$ $+37,607.6 . \mathrm{T}$, where $\mathrm{t}=$ time and $\mathrm{T}=$ temperature. Higher areas were obtained in the response surface with higher temperatures and higher exposure time, confirming that D-limonene really affected the total area of the chromatogram (Fig. 2b). The effect of high temperature and high exposure time favored the extraction of higher molecular weight compounds (essay 8, Fig. 1). It should be noticed that low molecular weight compounds also have odoriferous importance for orange juice (Mastello, Capobiango, et al., 2015; Mastello, Janzantti, et al., 2015) and they can be lost at high temperatures and high exposure times. HS-SPME conditions of temperature and exposure time affect in a different way the chromatogram regions. The chromatogram of essay 1 (Fig. 1) shows that lower temperature and exposure time favor the extraction of lower molecular weight compounds. The results made it necessary to evaluate another response apart from total area. It was decided to include the orange juice aroma representativeness as criteria, following the model of total area discounting D-limonene area. The orange juice aroma representativeness was evaluated using the sniffing test on the essays with higher exposure times (15-25 $\mathrm{min}$ ) and temperatures $\left(27-51{ }^{\circ} \mathrm{C}\right)$.

The panelists described the sniffing from the essay $8\left(51^{\circ} \mathrm{C}, 15 \mathrm{~min}\right)$ and essay $4\left(47^{\circ} \mathrm{C}, 22 \mathrm{~min}\right)$ as "cooked", "not natural", "not fresh" and low intensity of "characteristic of orange" aroma. The panelists described the essay $6\left(37^{\circ} \mathrm{C}, 25 \mathrm{~min}\right)$ and essay $2\left(27^{\circ} \mathrm{C}, 22 \mathrm{~min}\right)$ as "characteristic of orange", "natural", "fresh", "citric" and "peel oil". Descriptions of essay 6 and 2 were similar, indicating that temperatures up to $37^{\circ} \mathrm{C}$ with higher exposure time did not affect the orange juice natural and characteristic aroma. Moreover the chromatogram of essay 6 showed higher total area than the one of essay 2.

Based on the experimental design and sniffing data, the HS-SPME condition chosen was temperature of $37^{\circ} \mathrm{C}$ and exposure time of $25 \mathrm{~min}$ for the analysis of orange juice. Table 3 shows the volatile compounds areas of the HHP processed and non-processed orange juices analyzed by GC-FID. Forty-eight peaks were detected in the headspace of orange juices, corresponding to forty-nine compounds identified by GC-MS. The identified volatile compounds consisted of esters (4), alcohol (1), terpenes (38) and aldehydes (6). These compounds have already been identified in orange juice (Jordán, Goodner, \& Laencina, 2003; Mastello, Capobiango, et al., 2015; Mastello, Janzantti, et al., 2015; Rega et al., 2003). 42 compounds were significantly affected by HHP processing representing a total area of $72.10^{5} \mu \mathrm{V}$, and for the nonprocessed, $110.10^{5} \mu \mathrm{V}$. HHP processing conditions of time and pressure had an impact on volatile profile, even though high temperatures were not used (Table 3). Pasteurized orange juice was not analyzed in triplicate, so it was used only as reference and therefore, was not included in Table 3 .

D-Limonene, valencene, $\beta$-myrcene, linalool, octanal and decanal were the most abundant volatile compounds in the HHP processed and non-processed orange juices. Decanal was the only major compound not affected by HHP processing ( $p>0.05$ ). D-Limonene and $\beta$-myrcene areas were higher in the non-processed juice $(\mathrm{p} \leq 0.05)$, while valencene, linalool and octanal areas were higher in the HHP processed juice ( $\mathrm{p} \leq 0.05$ ). D-Limonene and $\beta$-myrcene are the most abundant terpenes in orange juice (Mastello, Capobiango, et al., 2015). The decrease in area of D-limonene of HHP processed orange juice might be explained by its conversion due to oxidation into $\alpha$-terpineol and terpinen-4-ol (Nijssen, 1991) which had peak area increased $(\mathrm{p} \leq 0.05)$ in the HHP processed orange juice (Table 3 ).
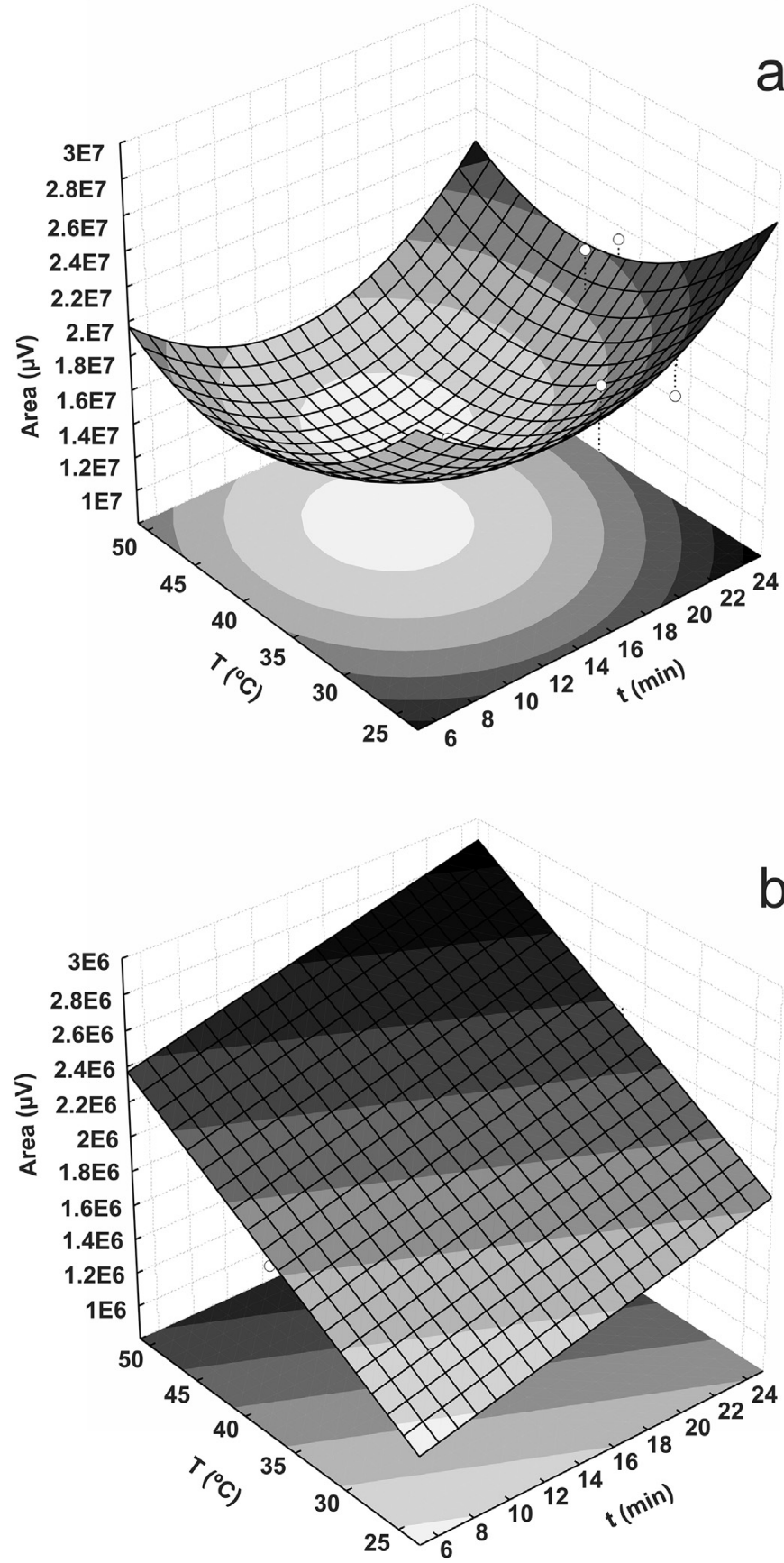

Fig. 2. Response surface of the effect of temperature (T) and exposure time (t) on the total area (a) and total area without limonene (b) of the GC-FID chromatogram. 
Table 3

Volatile compounds area $(\mu \mathrm{V})$ of HHP processed and non-processed orange juices.

\begin{tabular}{|c|c|c|c|c|c|}
\hline \multirow[t]{2}{*}{ Peak } & \multirow[t]{2}{*}{$\mathrm{RI}^{\mathrm{a}}$} & \multirow[t]{2}{*}{$\mathrm{RI}^{\mathrm{b}}$} & \multirow[t]{2}{*}{ Compound } & \multicolumn{2}{|l|}{ Area $(\mu \mathrm{V})$} \\
\hline & & & & HHP & Non-processed \\
\hline 1 & 800 & 1083 & Hexanal $^{\mathrm{c}, \mathrm{d}, \mathrm{e}}$ & *13977.1 (16.4) & $4372.8(8.5)$ \\
\hline 2 & 804 & 1038 & Ethyl butanoate $\mathrm{c}^{\mathrm{c}, \mathrm{d}, \mathrm{e}}$ & *16326.1 (4.3) & $6940.1(7.4)$ \\
\hline 3 & 903 & 1184 & Heptanal $^{\mathrm{d}, \mathrm{e}}$ & $1506.7(20.4)$ & $1064.4(6.2)$ \\
\hline 4 & 931 & 1022 & $\alpha$-Pinene ${ }^{\mathrm{c}, \mathrm{d}, \mathrm{e}}$ & $9446.4(7.1)$ & *15814.0 (2.4) \\
\hline 5 & 972 & 1118 & $\beta$-Pinene ${ }^{\mathrm{c}, \mathrm{d}, \mathrm{e}}$ & $5446.9(20.2)$ & ${ }^{*} 10576.2(2.4)$ \\
\hline 6 & 993 & 1167 & $\beta$-Myrcene ${ }^{\mathrm{c}, \mathrm{d}, \mathrm{e}}$ & $112,801.2(2.4)$ & *179264.6 (2.3) \\
\hline 7 & 1006 & 1288 & Octanal $^{c, \mathrm{~d}, \mathrm{e}}$ & *58833.1 (3.8) & $29,928.4(3.3)$ \\
\hline 8 & 1023 & 1264 & Cymene $^{\mathrm{d}, \mathrm{e}}$ & $5917.8(3.8)$ & *11183.4 (2.5) \\
\hline 9 & 1038 & 1200 & D-Limonene $e^{\mathrm{c}, \mathrm{d}, \mathrm{e}}$ & $6,443,629.2(2.7)$ & ${ }^{*} 10340822.9$ (2.6) \\
\hline 10 & $1043 / 1052$ & $1251 / 1264$ & Trans- $\beta$-ocimene $\mathrm{d}^{\mathrm{d}, \mathrm{e}}+$ cis- $\beta$-ocimene $^{\mathrm{d}, \mathrm{e}}$ & $2367.3(8.8)$ & $2186.5(2.8)$ \\
\hline 11 & 1059 & 1241 & $\gamma$-Terpinene $\mathrm{d}^{\mathrm{d}, \mathrm{e}}$ & $3855.3(2.6)$ & $6811.2(5.6)$ \\
\hline 12 & 1076 & 1565 & 1-Octanol ${ }^{c, d, e}$ & *21947.0 (3.5) & $14,078.1(0.4)$ \\
\hline 13 & $1085 / 1088$ & $1275 /-$ & Terpinolene (mixture) ${ }^{\mathrm{d}, \mathrm{e}}$ & $13,152.8(5.8)$ & $21212.9(4.9)$ \\
\hline 14 & 1105 & 1555 & Linalool ${ }^{\mathrm{c}, \mathrm{d}, \mathrm{e}}$ & *73970.8 (3.8) & $56,296.3(1.2)$ \\
\hline 15 & 1108 & 1401 & Nonanal $^{\mathrm{d}, \mathrm{e}}$ & $* 5763.7(5.0)$ & $5205.6(1.5)$ \\
\hline 16 & 1112 & 1382 & $p$-Mentha-1,3,8-triene $\mathrm{d}^{\mathrm{d}, \mathrm{e}}$ & *4048.8 (2.9) & $3729.8(1.0)$ \\
\hline 17 & 1131 & 1682 & Ethyl 3-hydroxyhexanoate ${ }^{\mathrm{d}, \mathrm{e}}$ & *4094.0 (5.4) & $2743.3(10.3)$ \\
\hline 18 & 1143 & 1367 & Alloocimene $\mathrm{e}^{\mathrm{d}, \mathrm{e}}$ & $3377.4(10.0)$ & $3044.7(2.0)$ \\
\hline 19 & 1177 & 1598 & Terpinen-4-ol ${ }^{\mathrm{c}, \mathrm{d}, \mathrm{e}}$ & *14343.4 (1.6) & $11,992.6(1.3)$ \\
\hline 20 & 1190 & 1698 & $\alpha$-Terpineol ${ }^{\mathrm{c}, \mathrm{d}, \mathrm{e}}$ & *7077.6 (4.6) & $5535.1(1.7)$ \\
\hline 21 & 1202 & 1435 & Ethyl octanoate ${ }^{\mathrm{d}, \mathrm{e}}$ & ${ }^{*} 1278.0(2.3)$ & $995.7(9.5)$ \\
\hline 22 & 1209 & 1499 & Decanal $^{\mathrm{c}, \mathrm{d}, \mathrm{e}}$ & $22,706.7$ (7.9) & $24,231.7(1.6)$ \\
\hline 23 & 1217 & 1476 & Octylacetate $\mathrm{d}^{\mathrm{d}, \mathrm{e}}$ & $4334.0(6.2)$ & 23190.8 (1.4) \\
\hline 24 & 1219 & 1865 & Carveol $^{\mathrm{d}, \mathrm{e}}$ & $2988.0(1.9)$ & $3382.4(4.6)$ \\
\hline 25 & 1230 & $1804+1772$ & Nerol $^{\mathrm{d}, \mathrm{e}}+\beta$-citronellol ${ }^{\mathrm{c}, \mathrm{d}, \mathrm{e}}$ & $9518.6(5.5)$ & *13544.6 (1.9) \\
\hline 26 & 1243 & 1722 & Carvone (mixture) ${ }^{\mathrm{d}, \mathrm{e}}$ & $2701.8(7.1)$ & $* 3485.7(0.7)$ \\
\hline 27 & 1257 & 1854 & Geraniol $^{\mathrm{d}, \mathrm{e}}$ & $1255.3(22.1)$ & $1365.1(11.8)$ \\
\hline 28 & 1259 & - & Linalylacetate $^{\mathrm{d}, \mathrm{e}}$ & $2919.6(21.3)$ & $* 4134.6(5.2)$ \\
\hline 29 & 1272 & 1768 & Perillaldehyde ${ }^{\mathrm{c}, \mathrm{d}, \mathrm{e}}$ & $1786.9(13.9)$ & $1744.9(15.7)$ \\
\hline 30 & 1309 & - & Undecanal $^{\mathrm{c}, \mathrm{d}, \mathrm{e}}$ & $674.0(10.9)$ & ${ }^{*} 1253.2(6.2)$ \\
\hline 31 & 1333 & - & ni & $14,112.4(4.0)$ & $14,855.2(1.9)$ \\
\hline 32 & 1349 & - & $\mathrm{ni}$ & $3784.1(17.9)$ & *5223.7 (9.3) \\
\hline 33 & 1357 & 1661 & Citronellylacetate $\mathrm{e}^{\mathrm{d}, \mathrm{e}}$ & $1236.5(7.3)$ & *3148.0 (2.8) \\
\hline 34 & 1368 & 1726 & Nerylacetate $^{\mathrm{d}, \mathrm{e}}$ & $832.9(13.6)$ & $2207.7(3.2)$ \\
\hline 35 & 1373 & 1444 & $\alpha$-Copaene $\mathrm{d}^{\mathrm{d}, \mathrm{e}}$ & $4590.2(2.6)$ & *5355.1 (4.1) \\
\hline 36 & 1384 & 1468 & $\delta$-Elemene ${ }^{\mathrm{d}, \mathrm{e}}$ & $1376.4(8.6)$ & *5103.0 (2.5) \\
\hline 37 & 1388 & 1757 & Geranylacetate $^{\mathrm{d}, \mathrm{e}}$ & $659.5(10.3)$ & $904.9(14.2)$ \\
\hline 38 & 1391 & 1687 & $\gamma$-Elemene ${ }^{\mathrm{d}, \mathrm{e}}$ & *11245.4 (3.7) & $9881.0(2.3)$ \\
\hline 39 & 1400 & 1537 & Longifolene $^{\mathrm{c}, \mathrm{d}, \mathrm{e}}$ & $3516.7(7.0)$ & 7440.1 (3.9) \\
\hline 40 & 1411 & $1707+1575$ & Dodecanal $^{\mathrm{d}, \mathrm{e}}+$ caryophyllene $^{\mathrm{d}, \mathrm{e}}$ & $7691.2(6.0)$ & $6465.7(1.9)$ \\
\hline 41 & 1426 & 1611 & $\beta$-Copaene ${ }^{\mathrm{d}, \mathrm{e}}$ & $1011.5(6.7)$ & 2047.7 (3.8) \\
\hline 42 & 1448 & 1647 & Humulene $\mathrm{e}^{\mathrm{d}, \mathrm{e}}$ & $* 5940.0(6.2)$ & $3842.5(3.2)$ \\
\hline 43 & 1492 & 1698 & Valencene $^{\mathrm{d}, \mathrm{e}}$ & *338953.9 (7.0) & $198,891.8(2.6)$ \\
\hline 44 & 1501 & 1715 & Eremophilene $^{\mathrm{d}, \mathrm{e}}$ & *6605.9 (6.7) & $4047.6(0.8)$ \\
\hline 45 & 1523 & 1740 & $\delta$-Cadinene $\mathrm{d}^{\mathrm{d}, \mathrm{e}}$ & *18386.7 (7.3) & $9550.2(2.2)$ \\
\hline 46 & 1578 & 1964 & Caryophileneoxide $\mathrm{d}^{\mathrm{d}, \mathrm{e}}$ & $880.9(17.1)$ & $344.3(5.8)$ \\
\hline 47 & 1654 & - & Selina-3,7 (11)-diene $\mathrm{e}^{\mathrm{d}, \mathrm{e}}$ & $* 2496.2(5.6)$ & $1139.5(7.6)$ \\
\hline 48 & 1800 & - & Nootkatone $\mathrm{d}^{\mathrm{d}, \mathrm{e}}$ & $* 2282.8(3.2)$ & $390.3(0.6)$ \\
\hline
\end{tabular}

Relative standard deviation in parenthesis.

$\mathrm{ni}=$ compound non identified.

${ }^{a}$ Retention index in HP-5MS column from GC-FID and GC-MS.

b Retention index in DB-Wax column from GC-MS.

c Compound identified by pure standards' retention time.

d Compound identified by mass spectrometry.

e Compound identified by the retention index.

${ }^{*} \mathrm{p} \leq 0.05$.

Hexanal, ethyl butanoate, octanal, 1-octanol, linalool, nonanal, $p$ mentha-1,3,8-triene, ethyl 3-hydroxyhexanoate, terpinen-4-ol, $\alpha$-terpineol, ethyl octanoate, $\gamma$-elemene, dodecanal, caryophyllene, humulene, valencene, eremophilene, $\delta$-cadinene, caryophilene oxide, selina-3,7(11)diene and nootkatone showed higher areas ( $\mathrm{p} \leq 0.05)$ in the HHP processed orange juice. The compounds with higher areas in the HHP processed juice were mainly of middle and low volatility (Table 3). Valencene might be converted into nootkatone by metal-catalyzed oxidation or photooxidation (Belitz, Grosch, \& Schieberle, 2009). It is usually affected by thermal processing (Vervoort et al., 2012).

$\alpha$-Pinene, $\beta$-pinene, $\beta$-myrcene, cymene, D-limonene, $\gamma$-terpinene, terpinolene, octyl acetate, carveol, nerol $+\beta$-citronellol, carvone, linalyl acetate, undecanal, citronellyl acetate, neryl acetate, $\alpha$-copaene, $\delta$-elemene, geranyl acetate, longifolene and $\beta$-copaene showed higher areas $(\mathrm{p} \leq 0.05)$ in the non-processed orange juice. They are mainly compounds with medium to high volatility (Table 3). Octyl acetate and linalyl acetate higher areas in the non-processed orange juice can be related to the higher areas of their correspondent alcohol or aldehyde in the HHP processed juice.

Perez-Cacho and Rouseff (2008) reported that concentrations of straight-chain aldehydes increase with heating and are higher in processed orange juices. Long-chained unsaturated fatty acids are precursors of many volatile compounds, including aliphatic saturated aldehydes. Three of the six aldehydes identified in our study were 
Table 4

Means of acceptance of color, overall impression, aroma, flavor and texture for the non-processed, pasteurized and HHP processed orange juices.

\begin{tabular}{|c|c|c|c|c|c|}
\hline Juice & Color & Overall Impression & Aroma & Flavor & Texture \\
\hline Non-processed & $6.65 \pm 1.68 \mathrm{a}$ & $6.22 \pm 1.61 \mathrm{a}$ & $6.65 \pm 1.38 \mathrm{a}$ & $6.10 \pm 1.83 a$ & $6.73 \pm 1.52 \mathrm{ab}$ \\
\hline Pasteurized & $7.04 \pm 1.37 a$ & $6.49 \pm 1.54 \mathrm{a}$ & $6.35 \pm 1.59 \mathrm{a}$ & $6.43 \pm 1.64 a$ & $6.84 \pm 1.57 \mathrm{a}$ \\
\hline HHP processed & $6.98 \pm 1.33 a$ & $5.31 \pm 1.89 b$ & $6.12 \pm 1.73 a$ & $5.08 \pm 2.14 b$ & $6.04 \pm 1.80 \mathrm{~b}$ \\
\hline
\end{tabular}

Means \pm standard deviation. Means with the same letter in each column did not differ in the Tukey test $(\mathrm{p} \leq 0.05) . \mathrm{N}=49$ consumers.

modified after HHP processing, hexanal $(\mathrm{p} \leq 0.05)$ and octanal ( $p \leq 0.05$ ) which areas were higher in the HHP processed orange juice, and undecanal which area was higher in the non-processed orange juice ( $\mathrm{p} \leq 0.05$ ) (Table 3 ), suggesting that HHP processing shows a similar effect as pasteurization.

Baxter et al. (2005) compared the HHP Australian Navel orange juice at $600 \mathrm{MPa}$ during $60 \mathrm{~s}$ to a pasteurized and a non-treated orange juice in six periods of storage at 4 and $10{ }^{\circ} \mathrm{C}$ over 12 weeks. Twenty selected volatile compounds were monitored, based on a previous work. Several compounds reported by Baxter et al. (2005) were not identified in this work, and some compounds reported here as important for the characterization of HHP processed, pasteurized and non-processed Pêra-Rio orange juice were not identified by them, e.g. 1-octanol, nootkatone, geranyl acetate, terpinolene, octyl acetate, carveol, carvone, linalyl acetate and $\delta$-elemene. They focused on differences of these 20 compounds previously identified in the literature during storage, but did not evaluate the volatile profile of the orange juice variety comprehensively as we did. At week zero volatile profile was similar among juices, apart from trans-2-hexenol and trans-2-pentenal total loss in the processed juices, and cis-3-hexenol and acetaldehyde in the pasteurized juice both at 4 and $10{ }^{\circ} \mathrm{C}$. After 12 weeks the volatile compounds concentration ranged from $6 \%$ to $38 \%$ of the original levels. Juice acceptability reduced with storage time and temperature. Vervoort et al. (2012) evaluated the volatile compounds of orange juice from equal proportions of Valencia, Pera and Baladi oranges. The juice was submitted to HHP processing ( $600 \mathrm{MPa}$ during $60 \mathrm{~s}$ ), pasteurization $\left(72{ }^{\circ} \mathrm{C}\right.$ for $20 \mathrm{~s}$ ) and PEF $\left(2 \mu \mathrm{s}\right.$ at $22 \mathrm{kV} \mathrm{cm}{ }^{-1}, 90 \mathrm{~Hz}$ and $130 \mathrm{~L} \mathrm{~h}^{-1}$ ) during storage at $4{ }^{\circ} \mathrm{C}$ in comparison to the non-treated juice. The main purpose was to investigate the potential of headspace fingerprinting, and not to study the contribution of each variety to the volatile compounds profile. No important differences were obtained among the juices based on the volatile profile of orange juice at the beginning of storage (day 1). At 28 days of storage some differences were observed, mainly related to microbial growth in non-processed juice and in degree of enzyme inactivation between PEF juice and HHP and pasteurized juices, the latter of which were similar. Our results showed differences in volatile profile between non-processed and HHP processed Pêra-Rio orange juice, which was similar to the pasteurized juice. In a general way, HHP processing is considered as another choice for orange juice processing, other than pasteurization. In the majority of the studies in which the influence of HHP processing on orange juice quality attributes has been studied, it is generally claimed to have similar or better quality, compared to pasteurized orange juices. The HHP processing conditions found in the literature usually apply high pressure and low temperature, within the industrial limits (Baxter et al., 2005; Timmermans et al., 2011; Vervoort et al., 2011). These studies confirm that the orange variety, maturity, extraction and processing conditions can indeed affect the volatile profile, and highlights the importance and industrial relevance of the present study. This study was based on the conditions described by Bisconsin-Junior et al. (2014) (520 MPa, $60{ }^{\circ} \mathrm{C}$ ), for both equivalent microbial and enzyme inactivation among the juices. Similar conditions of pressure and temperature have been described in the literature by using laboratory-scale equipment (Sampedro et al., 2009). Sampedro et al., 2009 showed that, when compared with HHP, PEF treatment achieved a similar PME inactivation than thermal processing with a better orange juice-milk beverage fresh aroma. But, the most satisfactory condition for current industrial equipment is $650 \mathrm{MPa}$ at $20-30{ }^{\circ} \mathrm{C}$, because it can indeed provide orange juice with better flavor retention.

When orange juice is heated during pasteurization, a complex series of chemical reactions occur, leading to losses of compounds, which can affect the aroma of orange juice (Perez-Cacho \& Rouseff, 2008). HHP processing could enhance or retard enzymatic and chemical reactions, which could lead to changes in overall aroma profile (El Hadi et al., 2013; Vervoort et al., 2012; Viljanen, Lille, Heinio, \& Buchert, 2011). Our results showed that orange juice volatile compounds were affected by HHP processing in a similar way as pasteurization.

Sensory results showed acceptance means for color, overall impression, aroma, flavor and texture from 5.08 to 7.04, between the terms "neither like nor dislike" and "liked very much", for either HHP processed, non-processed and pasteurized orange juices. No difference ( $p>0.05$ ) was found among the juices for color and aroma. Overall impression and flavor means were higher ( $\mathrm{p} \leq 0.05$ ) for non-processed and pasteurized orange juices, and texture mean was higher ( $\mathrm{p} \leq 0.05)$ for pasteurized (Table 4). The non-processed orange juice was stated by some consumers as "faded color", "natural orange juice aroma and flavor", "sour taste", "weak sweet taste" and "cloud loss". The HHP processed orange juice was considered as having "intense color", "artificial aroma and flavor", "sour taste", "a little bitter" and "lack of sweet". The pasteurized orange juice was stated as "artificial aroma and flavor", "sour taste", "weak flavored" and "bad taste".

Principal Component Analysis (PCA) was used to represent data of volatile compounds area and acceptance means in two dimensions to discriminate HHP processed (HHP), non-processed (NP) and pasteurized (PAST) orange juices (Fig. 3). Pasteurized orange juice volatile profile was included in PCA just for comparison purpose. PCA was suitable to differentiate the juices and to group the volatile compounds according to their spatial location. The HHP processed orange juice was loaded positively in PC1 and PC2, the pasteurized orange juice was loaded positively in PC1 and negatively in PC2 and the non-processed orange juice was loaded negatively in PC1 and PC2. PC1 allowed to differentiate processed from non-processed orange juice, while PC2 allowed the discrimination of HHP from pasteurized juice. PC1 was mainly influenced (rotate component matrix $\geq 0.95$ ) by loading positively the compounds ethyl butanoate (0.99), octanal (0.99), 1-octanol (0.99), linalool (0.96), ethyl 3-hydroxyhexanoate (0.99), and nootkatone (0.97) and color acceptance (0.99), characterizing both HHP processed and pasteurized orange juices; and negatively the compounds terpinolene $(-0.99)$, octyl acetate $(-0.99)$, carveol $(-0.99)$, carvone $(-0.96)$, linalyl acetate $(-0.96)$ and $\delta$-elemene $(-0.97)$, characterizing non-processed orange juice. PC2 was mainly influenced (rotate component matrix $\geq 0.95$ ) by loading positively ethyl octanoate (0.99), characterizing HHP processed orange juice, and negatively geranyl acetate $(-0.96)$ and overall impression $(-0.97)$ and flavor acceptance $(-0.97)$, characterizing pasteurized orange juice.

Although HHP processing showed a similar effect on volatile profile as pasteurization, sensory acceptance pointed out difference in flavor that can be attributed to non-volatile compounds. HHP can affect macromolecules related to food quality properties (Oey et al., 2008). Finally, is should be considered HHP as a promising technique, even though the original fresh sensory properties are not always fully retained. 


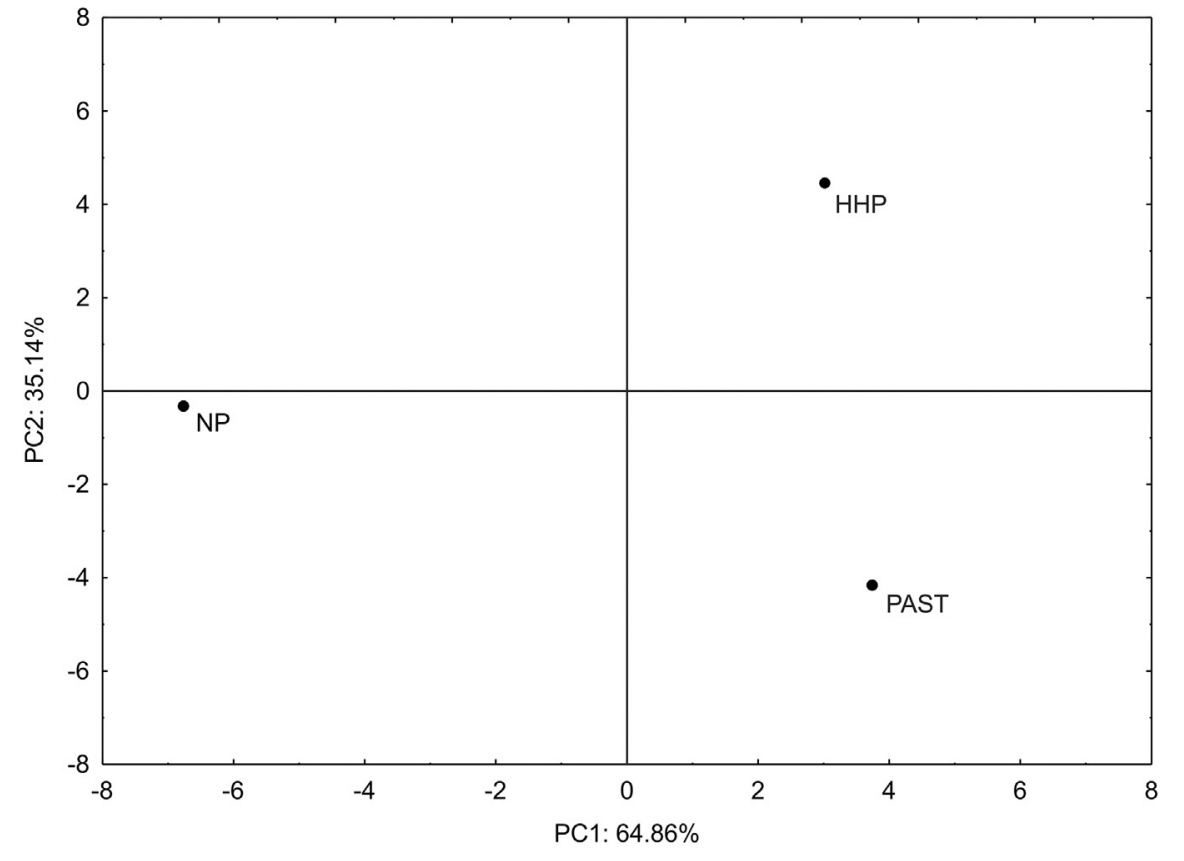

Fig. 3. PCA of the volatile compounds area and sensory acceptance means of HHP processed (HHP), non-processed (NP) and pasteurized (PAST) orange juices. Volatile compounds peak numbers correspond to those from Table 3.

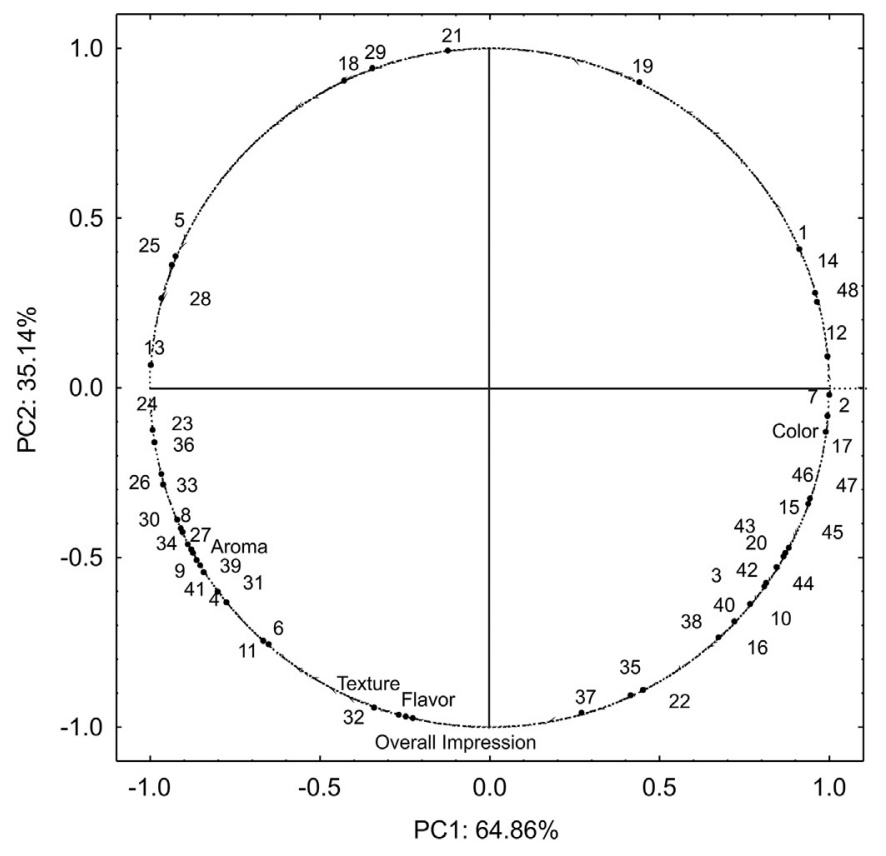

\section{Conclusion}

The optimization of HS-SPME conditions is essential for orange juice volatile compounds analysis. RSM and sniffing were successfully applied for this purpose, considering the characteristics of the volatile profile of orange juice matrix. The chosen HS-SPME conditions $37{ }^{\circ} \mathrm{C}$ during $25 \mathrm{~min}$ of exposure time properly characterized the volatile profile of HHP processed, pasteurized and non-processed orange juices. HHP processing conditions of time and pressure had an impact on volatile profile.

Sensory acceptance allowed noticing differences mainly in flavor but not in aroma of HHP processed and pasteurized orange juice and the non-processed orange juice was the most accepted.

PCA highlighted differences between processed and non-processed orange juice, and also discriminated HHP from pasteurized orange juice. HHP processed orange juice was characterized by ethyl butanoate, octanal, 1-octanol, linalool, ethyl 3-hydroxyhexanoate, nootkatone and ethyl octanoate. Pasteurized orange juice was characterized by the same compounds as HHP, plus geranyl acetate and apart from ethyl octanoate. Terpinolene, octyl acetate, carveol, carvone, linalyl acetate and $\delta$-elemene characterized non-processed orange juice.

\section{Acknowledgements}

This work was supported by São Paulo Research Foundation (FAPESP) [grant 2009/15084-0]; CNPq [process 483785/2010-5]; and PADC/FCF/UNESP [process 2013/14-1].

\section{References}

Achir, N., Dhuique-Maye, C., Hadjal, T., Madani, K., Pain, J.-P., \& Dornier, M. (2016). Pasteurization of citrus juices with ohmic heating to preserve the carotenoid profile. Innovative Food Science \& Emerging Technologies, 33, 397-404. 
Acree, T., \& Arn, H. (2016). Flavornet. Retrieved from http://www.flavornet.org/ flavornet.html, Accessed date: 9 October 2016.

Bajovic, B., Bolumar, T., \& Heinz, V. (2012). Quality considerations with high pressure processing of fresh and value added meat products. Meat Science, 92, 280-289.

Baxter, I. A., Easton, K., Schneebeli, K., \& Whitfield, F. B. (2005). High pressure processing of Australian navel orange juices: Sensory analysis and volatile flavour profiling. Innovative Food Science \& Emerging Technologies, 6, 372-387.

Belitz, H.-D., Grosch, W., \& Schieberle, P. (2009). Aroma compounds. In S. B. Heidelberg (Ed.). Food chemistry (pp. 340-402). Berlin: Buchbinderei Stein \& Lehmann.

Bisconsin-Junior, A., Rosenthal, A., \& Monteiro, M. (2014). Optimisation of high hydrostatic pressure processing of Pêra Rio orange juice. Food and Bioprocess Technology, 7, 1670-1677.

Braddock, R. J. (1999). Single strength orange juices and concentrate. In R. J. Braddock (Ed.). Handbook of citrus by-products and processing technology (pp. 53-83). (2nd ed.). New York: John Wiley \& Sons.

Bull, M. K., Zerdin, K., Howe, E., Goicoechea, D., Paramanandhan, P., \& Stockman, R. (2004). The effect of high pressure processing on the microbial, physical andchemical properties of Valencia and Navel orange juice. Innovative Food Science \& Emerging Technologies, 5, 135-149.

Bylaite, E., \& Meyer, A. S. (2006). Characterisation of volatile aroma compounds of orange juices by three dynamic and static headspace gas chromatography techniques. European Food Research and Technology, 222, 176-184.

CitrusBR (2017). Brazilian Association of Citrus Exporters. Retrieve from http://www. citrusbr.com/revista/maio2017, Accessed date: 30 June 2017.

El Hadi, M. A. M., Zhang, F.-J., Wu, F.-F., Zhou, C.-H., \& Tao, J. (2013). Advances in fruit aroma volatile research. Molecules, 18, 8200-8229.

Janzantti, N. S., Machado, T. V., \& Monteiro, M. (2011). Sensory acceptance of juice from FCOJ processing steps. Journal of Sensory Studies, 26(5), 322-330.

Jordán, M. J., Goodner, K. L., \& Laencina, J. (2003). Deaeration and pasteurization effects onthe orange juice aromatic fraction. Lebensmittel-Wissenschaft und Technologie, 36(4), 391-396.

Macfie, H. J., Bratchell, N., Greenhoff, K., \& Vallis, L. V. (1989). Designs to balance the effect of order of presentationand first-order carry-over effects in hall tests. J. Sens. Stud. 4, 129-148.

Mastello, R. B., Capobiango, M., Chin, S., Monteiro, M., \& Marriott, P. J. (2015). Identification of odour-active compounds of pasteurised orange juice using multidimensional gas chromatography techniques. Food Research International, 75 281-288.

Mastello, R. B., Janzantti, N. S., \& Monteiro, M. (2015). Volatile and odoriferous compounds changes during frozen concentrated orange juice processing. Food Research International, 77, 591-598.

Montgomery, D., \& Wiley, S. J. (2001). Design and analysis of experiments (5th ed.). New York: John Wiley \& Sons, Inc.

Murat, C., Gourrat, K., Jerosch, H., \& Cayot, N. (2012). Analytical comparison and sensory representativity of SAFE, SPME, and purge and trap extracts of volatile compounds from pea flour. Food Chemistry, 135, 913-920.

Myers, R. H., Montgomery, D., \& Anderson-Cook, C. M. (2009). Response surface methodology: Process and product optimization using designed experiments. New York: John Wiley \& Sons, Inc.

Nagy, S., \& Chen, C. S. (1993). Orange and tangerine juices. In P. E. Shaw (Ed.). Fruit juice processing technology (pp. 111-135). Auburndale, FL: Agscience, Inc.

Neves, M. F., Trombin, V. G., Milan, P., Lopes, F. F., Cressoni, R., \& Kalaki, R. (2009). In Marketstrat (Ed.). O Retrato da Citricultura Brasileira (138 pp)Centro de pesquisas e projetos em marketing e estratégia. Retrieved from http://www.citrusbr.com/ download/Retrato_Citricultura_Brasileira_MarcosFava.pdf, Accessed date: 7 October 2017.
Nijssen, B. (1991). Off-flavors. In M. Henk (Ed.). Volatile compounds in food and beverages (pp. 689-722). (1st ed.). USA: Marcel Dekker, Inc.

Oey, I., Lille, M., Loey, A. V., \& Hendrickx, M. (2008). Effect of highpressureprocessing on colour, texture and flavour of fruit- and vegetable-based food products: A review. Trends in Food Science \& Technology, 19, 320-328.

Parish, M. E. (1998). High pressure inactivation of Saccharomyces cerevisiae, endogenous microflora and pectin methylesterase in orange juice. Journal of Food Safety, 18, 57-65.

Perez-Cacho, P. R., \& Rouseff, R. L. (2008). Processing and storage effects on orange juice aroma: A review. Journal of Agricultural and Food Chemistry, 56, 9785-9796.

Rega, B., Fournier, N., \& Guichard, E. (2003). Solid phase microextraction (SPME) of orange juice flavor: Odor representativeness by direct gas chromatography Olfactometry (D-GC-O). Journal of Agricultural and Food Chemistry, 51, 7092-7099.

Rendueles, E., Omer, M. K., Alvseike, O, Alonso-Calleja, C. Capita, R. \& Prieto, M. (2011). Microbiological food safety assessment of high hydrostatic pressure processing: A review. LWT-Food Science and Technology, 44, 1251-1260.

Samani, B. H., Khoshtaghaza, M. H., Lorigooini, Z., Minaei, S., \& Zareiforoush, H. (2015). Analysis of the combinative effect of ultrasound and microwave power on Saccharomyces cerevisiae in orange juice processing. Innovative Food Science \& Emerging Technologies, 32, 110-115.

Sampedro, F., Geveke, D. J., Fan, X., \& Zhang, H. K. (2009). Effect of PEF, HHP and thermal treatment on PME inactivation and volatile compounds concentration of an orange juice-milk based beverage. Innovative Food Science \& Emerging Technologies, 10, 463-469.

Timmermans, R. A. H., Mastwijk, H. C., Knol, J. J., Quataert, M. C. J., Vervoort, L., Van der Plancken, I., ... Matser, A. M. (2011). Comparing equivalent thermal, high pressure and pulsed electric field processes for mild pasteurization of orange juice. Part I: Impact on overall quality attributes. Innovative Food Science \& Emerging Technologies, 12, 235-243.

United States Department of Agriculture (2016). Citrus: World Market and Trade. Retrieved from http://apps.fas.usda.gov/psdonline/circulars/citrus.pdf, Accessed date: 16 November 2016.

van Den Dool, H., \& Kratz, P. (1963). A generalization of the retention index system includinglinear temperature programmed gas-liquid partition chromatography. Journal of Chromatography A, 11, 463-471.

Velázquez-Estrada, R. M., Hernández-Herrero, M. M., Guamis-López, B., \& Roig-Sagués, A. X. (2012). Impact of ultra high pressure homogenization on pectin methylesterase activity and microbial characteristics of orange juice: A comparative study against conventional heat pasteurization. Innovative Food Science \& Emerging Technologies, 13, 100-106.

Vervoort, L., Grauwet, Kebede, B. T., Van der Plancken, I., Timmermans, R., Hendrickx, M., \& Loey, V. (2012). Headspace fingerprinting as an untargeted approach to compare novel andtraditional processing technologies: A case-study on orange juice pasteurisation. Food Chemistry, 134, 2303-2312.

Vervoort, L., Van der Plancken, I., Grauwet, Kebede, B. T., Timmermans, R., Mastwijk, H. C., ... Loey, V. (2011). Comparing equivalent thermal, high pressure and pulsed electric field processes for mild pasteurization of orange juice. Part II: Impact on specific chemical and biochemical quality parameters. Innovative Food Science \& Emerging Technologies, 12, 466-477.

Viljanen, K., Lille, M., Heinio, R., \& Buchert, J. (2011). Effect of high pressure processing on volatile composition and odour of cherry tomato purée. Food Chemistry, 129 1759-1765.

Wang, R., Xu, Q., Yao, J., Zhang, Y., Liao, X., \& Hu, X. (2013). Post-effects of high hydrostatic pressure on green color retentionand related properties of spinach puree during storage. Innovative Food Science \& Emerging Technologies, 17, 63-71. 